\title{
Genética y Justicia: Tratar la enfermedad, respetar la diferencia *
}

\author{
MARTHA C. NUSSBAUM \\ University of Chicago
}

RESUMEN. Las nuevas posibilidades abiertas por la investigación científica, especialmente en el campo de la genética, por un lado generan interrogantes morales hasta ahora desconocidos y, por otro, nos obligan a reformular de una manera totalmente nueva cuestiones y conceptos que hasta ahora funcionaban de forma adecuada. Así ocurre, por ejemplo, con las teorías de la justicia: estamos acostumbrados a que exista un acuerdo relativamente amplio en torno al concepto de persona, y la discusión se suele centrar en el tipo de bienes que habrían de distribuirse entre un conjunto dado de individuos. Pero la posibilidad de transformar los talentos personales y, así, modificar algunos rasgos de nuestra población de acuerdo con criterios actuales, abre un importante debate en la medida en que dichos cambios pueden considerarse recursos y, así, objeto de redistribución. Por otro lado, el hecho de que ciertas alteraciones puedan o incluso deban realizarse con vistas al bien de futuros individuos conlleva el riesgo de que se abra paso una homogeneización social empobrecedora o de que se eliminen valiosas formas de vida y de cultura. Dado que esta incipiente posibilidad plantea aporías y amenazas inquietantes, la reflexión rigurosa constituye una herramienta crítica fundamental e imprescindible.
ABSTRACT. The new possibilities opened up by scientific research, particularly in the area of genetic, raise hitherto unknown moral perplexities and, at the same time, do force us to rethink questions and redefine concepts which use to work adequately up to now. So, for example, regarding to theories of justice: we are used to having a relatively broad agreement on the concept of person, and the discussion was usually focused on the kind of goods which must be distributed to a given group of people. But the possibility of transforming people by changing their talents, and in this way, transforming some features of the population according to certain current criteria, opens up an important discussion insofar those transformations could be considered resources and, if so, been redistributed themselves. However, the fact that some sort of alterations could or, even more, should be made in order to achieve the good for future children embodies the risk consisting in the impoverishment and homogenization of the society, or the obliteration of valuable forms of life and culture. Since this incipient possibility arises paradoxes and disturbing threats, the rigorous reflection represents a basic indispensable critical tool.

* Traducción de Rocío Orsi.

El Consejo de Redacción de Isegoría agradece al Prof. Eduardo Mendieta las gestiones realizadas para la publicación en nuestra revista de los artículos de Marta Nussbaum y Peter Singer. 
Katherine y Bill concurren al mismo puesto directivo en una gran empresa. La solicitud de Katherine incluye un certificado de mejoramiento genético de Opti-Gene, el cual establece que su titular ha adquirido un conjunto de servicios genéticos destinados a aumentar la memoria y potenciar el sistema inmunológico. Bill, que no se puede permitir un mejoramiento genético, objeta que un contrato basado en la mejora genética supone una violación de la igualdad de oportunidades: el trabajo debería adjudicarse en función del mérito. Katherine replica que adjudicar el trabajo en función del mérito significa que el puesto corresponde al mejor candidato, y ella es la mejor candidata, de manera que ¿dónde está el problema? ${ }^{1}$.

Nuestro creciente conocimiento del genoma humano plantea complejos interrogantes éticos. Algunos de ellos son una extensión de viejas perplejidades. Así, en cierto sentido, la disputa Katherine-Bill no dista mucho de los problemas relativos a la igualdad de oportunidades que durante largo tiempo hemos estado debatiendo. Tanto Katherine, que se ha visto favorecida por una mayor atención a su salud y a su mente debido a una educación de clase media, como Bill, que se ha favorecido menos debido a su pobreza y a circunstancias desfavorables, contarían con defensores en el consabido debate sobre el sentido de la igualdad de oportunidades en un contexto de desigualdad social. Teniendo claro que Katherine heredó sus buenas cualidades de los genes de sus padres y Bill sus defectos de los genes de los suyos, la mayoría de los americanos diría: bien, son quienes son. Pero ciertos igualitaristas mantendrían que no merecen obtener ninguna ventaja de aquellos rasgos que tienen por nacimiento. Mantendrían que de todos modos el trabajo probablemente debiera adjudicarse a Katherine, pero la estructura general de la sociedad, en lo que toca a recompensas y oportunidades, debería modificarse de manera que proporcionase a Bill una ayuda adicional. Los talentos de Katherine constituyen recursos sociales que deben emplearse equitativamente en provecho de todos.

Pero el espacio moral abierto por este caso no nos es del todo familiar. La controversia entre Katherine y Bill también plantea algunas cuestiones que no se pueden abordar a partir de las teorías éticas actuales. Todas las teorías éticas actuales establecen algún tipo de distinción entre el reino de la naturaleza o del azar y el reino de la justicia. Aunque no queda claro dónde está la línea divisoria en cada caso particular, parece como si nuestro sentido global de la vida dependiera de la existencia de dicha distinción. Algunas cosas que nos van mal son sólo tragedias, se encuentran más allá del control humano;

${ }^{1}$ Este ejemplo está tomado de From Chance to Choice: Genetics and Justice, de Allen Buchanan, Dan W. Brock, Norman Daniels y Daniel Wikler (Nueva York y Cambridge, Inglaterra, Cambridge University Press, 2000). El presente artículo tiene su origen en una reseña de este excelente libro publicada en The New Republic, diciembre, 4, 2000. 
otras se podrían haber evitado o controlado con una mejor planificación social y, de este modo, son propias del reino de la justicia social. La naturaleza no parece que vaya a desaparecer por ahora y, en cualquier caso, a todos nos aguarda un triste final. Pero lo que la historia de Katherine y Bill nos revela es que vivimos en un tiempo caracterizado por «la colonización de lo natural por lo justo» ${ }^{2}$. Muchas cosas que siempre se han visto como accidentes inmutables ahora parece que las podemos cambiar, y que tenemos incluso la obligación de cambiarlas.

En todo caso, la reflexión en torno a la justicia tendrá que sufrir una ligera variación. Estamos acostumbrados a pensar sobre la justicia en términos de distribución de cosas a la gente, de modo que las personas siguen siendo quienes son y se conciben compartiendo un conjunto de necesidades y de habilidades. Sin embargo, desde el momento en que somos capaces de modificar a las personas en aspectos esenciales, debemos tener en cuenta que la justicia puede exigir algunas alteraciones sobre las mismas: pues la buena salud y la rápida memoria de Katherine no son precisamente propiedades superficiales, como lo es un nuevo corte de pelo. Y una vez que emprendamos este camino seguramente nos daremos cuenta de que no está nada claro lo que estamos promoviendo, pues la idea de una naturaleza humana constante empieza a escapársenos de las manos. Y nociones como «florecimiento humano» o los «bienes primarios» que supuestamente todos los seres humanos necesitamos para vivir parecen estar a punto de escaparse con ella.

Algunos enfoques sobre estas cuestiones éticas propuestos por ciertos filósofos para aconsejar a los agentes políticos han sido extremadamente inadecuados. Por ejemplo, la sección «Filosofía» del informe sobre la clonación de la Comisión Nacional de Bioética es una vergüenza, un fárrago torpe de viejas ideas mal asimiladas desfilando como si respaldaran una prohibición sobre la clonación, si bien no lo hacen. (Por poner sólo un ejemplo, se me atribuye la invención del concepto de «separabilidad de las personas», un concepto más viejo que Matusalén y prominente en el pensamiento tanto de Aristóteles como de Kant, y encima se alega que este concepto muestra que la clonación es mala. Pero en ningún caso la separabilidad de las personas muestra tal cosa: la separabilidad es simplemente una forma de referirse al hecho de que cada persona tiene exactamente una vida que vivir, y que las políticas que persiguen el bien común sin pensar en el bien de cada persona son por ello mismo injustas o incluso explotadoras del individuo. ¿Qué tiene esto que ver con la clonación? También se hace un uso equivocado del concepto de Joel Feinberg, éste sí que fue inventado por él, de «derecho a un futuro abierto». Esta norma tiene que ver con el derecho a una variedad de elecciones y oportunidades, y no se viola por el hecho de ser el doble genético de alguna otra persona). En general, la autoridad filosófica se usa sin calidad filosófica para prestar apoyo al miedo a la novedad.

\footnotetext{
${ }^{2}$ De nuevo, esta frase ha sido acuñada por Buchanan et al.
} 
Pero existe algún trabajo reciente bastante mejor, pues pone de manifiesto que la filosofía puede ser a la vez rigurosa y accesible al público. From Chance to Choice: Genetics and Justice, escrito por cuatro filósofos punteros en el área de la ética médica, constituye un ejemplo de cómo un trabajo filosófico detallado y riguroso nos puede ayudar a abrirnos paso a través de las perplejidades que plantea la ingeniería genética. Por decirlo clara y brevemente, argumentan que deberíamos emplear nuestro nuevo conocimiento genético para tratar defectos en relación a un umbral de habilidades y funciones humanas básicas, pero no necesariamente (en la mayoría de los casos) para ofrecer mejoramientos de las habilidades humanas por encima de dicho umbral; que deberíamos proteger celosamente la libertad reproductiva, criticando la mayoría de las tentativas (pero no todas) de persuadir u obligar a los padres a tener un cierto tipo de hijos; que la orientación genética y determinados servicios genéticos deberían ofrecerse en todos los planes de seguridad social; que la sociedad debería evolucionar hacia un aumento del respeto y la inclusión de los discapacitados, pero esta consideración no debería retraernos a la hora de tratar serios defectos genéticos en la medida en que podamos. Pero los autores no son profesionales de la política, son filósofos; y en lo que toca a la filosofía, las conclusiones obtenidas valen poco sin los argumentos de los que derivan. La contribución más admirable de From Chance to Choice estriba en la densidad y la contundencia de sus argumentos.

\section{II}

¿Por qué deberíamos ocuparnos de lo que tienen que decirnos los argumentos filosóficos en la era del cambio científico? La respuesta de los autores sería que si no lo hacemos corremos el riesgo de pensar incorrectamente. Cuando hacemos frente a las nuevas y apabullantes posibilidades abiertas por el proyecto Genoma Humano, nos aguardan tres obstáculos que se interponen al buen ejercicio del pensamiento. En primer lugar, enseguida se apodera de nosotros el simple miedo al cambio. Es muy fácil retroceder con horror ante la idea misma de tratamiento y mejoramiento genético sólo porque no sabemos muy bien qué decir al respecto. La mera posibilidad amenaza nociones que han conformado nuestros cimientos morales durante siglos. En lugar de pensar fría y analíticamente, a menudo hacemos oscuras advertencias sobre los peligros de «jugar a ser Dios» o de apartarse de la «naturaleza».

Además, tal como los autores afirman duramente, un pensamiento serio y sistemático no remplaza a este tipo de charlas. Ya estamos «jugando a ser Dios» de numerosas formas: realizamos inoculaciones, tratamos enfermedades o buscamos nuevos planes educativos para afrontar los problemas de aprendizaje. En muchos campos de nuestras vidas no permanecemos pasivos frente a la naturaleza. Y es difícil que la «naturaleza» constituya una norma moral para una persona en sus cabales. (Tal como observó J. S. Mill, «Matar, el 
acto más criminal reconocido por las leyes humanas, es algo que la Naturaleza realiza una vez sobre todos los seres que viven»). De manera que lo que hace falta no es ni pánico ni piedad, sino, más bien, una evaluación sobria y sistemática de las nuevas posibilidades de mejora abiertas por nuestro reciente conocimiento genético.

El segundo obstáculo a la buena deliberación en el área de la investigación genética es una especie de gen-fetichismo que ha gozado siempre de cierto atractivo, pero que se ha vuelto más común en los últimos tiempos. Nos gusta decir: «todo está en los genes», queriendo decir que en realidad el ambiente no tiene nada que ver con lo que ocurra, de modo que no tenemos obligación alguna de promover buenas condiciones ambientales. Desde este punto de vista, la respuesta adecuada a la biología es la resignación, y las desigualdades son siempre resultado del destino. Los autores dedican mucho tiempo a desenmarañar los malentendidos producidos por la causalidad genética, valiéndose de un excelente apéndice científico realizado por el filósofo de la ciencia Eliot Sober.

Sober proporciona un detallado análisis de las complejas interrelaciones entre los genes y el ambiente, y arguye que la cuestión que se debería plantear es la de cuál es la importancia relativa de los factores genéticos y ambientales en cada caso, ya que ambos factores están siempre causalmente implicados. «Una afección tiene un componente genético o ambiental significativo sólo en relación con un conjunto de genes y un conjunto de ambientes». Es más, en ocasiones la genética produce resultados de forma indirecta, mediante un cambio en el ambiente del individuo: una diferencia física puede provocar que una persona sea tratada de manera diferente, dando lugar así a diferencias conductuales. Sober es especialmente crítico con la idea de que un fenómeno tan complejo humana y psicológicamente como el deseo homosexual pueda, plausiblemente, localizarse en un simple gen.

Y no menos importante es el ataque de los autores a la función ideológica del determinismo genético. «Si existiera un ser omnipotente y omnisciente», escriben,

que estuviera comprometido resueltamente a proteger del examen crítico el orden social y político actual, es improbable que pudiera dar con una estrategia mejor que implantar el determinismo genético en las mentes de la gente. Por supuesto que no existe semejante demonio maligno. Sin embargo, hay científicos que a veces manifiestan una gen-manía que consiste en una combinación de entusiasmo excesivo por sus propios proyectos y una ansiosa retórica de relaciones públicas orientada a asegurarse apoyo social y económico. Y existen empresas biotecnológicas listas para dar rienda suelta a sofisticadas técnicas de marketing que sin duda estimularán esperanzas poco realistas en soluciones genéticas para todo tipo de problemas.

De hecho, los autores muestran que las nuevas posibilidades genéticas harían más difícil que la gente camuflara su quietismo con razones genéticas. Después 
de todo, si podemos alterar los genes, éstos entran a formar parte del ambiente social como cualquier otra cosa, y tenemos que pensar seriamente en el cambio ambiental y su relación con la justicia, queramos o no.

El tercer obstáculo que se opone al buen pensar en estos nuevos tiempos, el mayor con diferencia, es la sensiblería, la dejadez y la falta de un esfuerzo sistemático que caracteriza a la mayoría del pensamiento humano en torno a la mayoría de los temas en la mayoría de momentos y lugares. La metodología de los autores en este libro es básicamente socrática: asumen que la mayoría de la gente tiene muchas intuiciones éticas sensatas y pertinentes para resolver estos dilemas, pero están convencidos de que sin un examen constante, sin una comprobación de las teorías y principios, así como sin la construcción de sistemas complejos que integren los juicios particulares en un todo coherente, no afrontaremos el futuro correctamente. Creen que si esto es así en áreas donde hechos y conceptos son familiares, lo será en mucha mayor medida en campos donde nuevas posibilidades científicas nos exigen una revisión de algunos de nuestros conceptos y principios más básicos.

Aquí, desde su punto de vista, es donde entra la filosofía. Los autores, especialistas en ética médica, pero también ampliamente interesados en materia de justicia social, distinguen cuidadosamente su proyecto de un enfoque demasiado habitual en ética médica, donde la gente simplemente ensarta unos pocos principios consabidos, desvinculados de cualquier teoría global, y se limita a aplicarlos a casos particulares. Este tipo de enfoques difícilmente merece el título de filosofía, tal como los autores dan a entender con su desprecio. Sin embargo, los autores creen, junto con Sócrates, Aristóteles, Sidgwick y John Rawls, que un buen trabajo filosófico tiene que ser difícil, complejo y sistemático. Hay que considerar tanto los juicios de la gente como las teorías más importantes que se encargan de articular dichos juicios. Cuando se atiende a decisiones genéticas, un pensador serio debe integrar este debate en una consideración global sobre instituciones sociales e igualdad de oportunidades. Aunque inevitablemente una investigación de este tipo tiene que partir de algún sitio - y los autores parten de un tipo conocido de teoría liberal de la justicia, próxima a la de John Rawls - dan muestras a lo largo del libro de buena disposición para considerar una variedad de enfoques alternativos y evaluar teorías a través de los juicios a que dan lugar, así como para evaluar juicios según su relación con las teorías. Sostienen que esta forma holística de argumentar es mucho más importante en esta área que en otras áreas de la filosofía política, pues es aquí donde una teoría poco común tiene muchas posibilidades de producir conceptos totalmente adecuados. Es importante pensar cómo las teorías de igualdad de oportunidades actuales son relevantes para el dilema de Katherine y Bill; pero es igualmente importante entender en qué momento dichas teorías dejan de ser adecuadas, y en qué sentido necesitan mejorarse.

Los autores dedican un capítulo a discutir sobre orientación genética y decisiones relativas a la concepción; pero dada su familiaridad, este asunto 
ocupa un espacio menor que una cierta cantidad de temas acerca de los cuales se ha escrito poco hasta ahora, la mayoría relacionados con la cirugía o alteración genética, tales como: ¿Qué tratamientos genéticos deberían ofrecerse, y deberían exigirse como parte de la atención sanitaria básica? ¿Podemos diferenciar con algún sentido entre tratamientos y mejoramientos genéticos y, de ser así, deberían subvencionarse también los mejoramientos, o reservarse a la elección individual? ¿Debería permitirse que los grupos que sostienen una determinada concepción de la vida buena desarrollen proyectos genéticos que contribuyan a perpetuar las características valoradas por dichos grupos, aislándose así progresivamente de la sociedad que los rodea? ¿Debería constituir una medida de salud pública la revisión médica de defectos genéticos extendidos entre la población? ¿Debería acusarse de negligencia a los padres que no aprovecharan las ventajas derivadas de la posibilidad de mejorar la suerte de sus hijos? ¿Cómo podemos defender coherentemente la libertad reproductiva en una era en la que sabemos demasiado acerca del niño que va a nacer? Finalmente, ¿qué repercusión tienen las nuevas posibilidades genéticas sobre el estatus social de los discapacitados? ¿Pueden éstos reivindicar legítimamente que no se lleven a cabo programas de paliativos genéticos sobre la base de que dichos cambios en la población aumentarían progresivamente su aislamiento y estigmatización?

Nuestro temor a la intervención genética no es simplemente un temor irracional. Tiene raíces históricas: recordamos los excesos y las vejaciones del movimiento en pro de la eugenesia de principios del siglo xx, las esterilizaciones forzadas de los «no aptos», la cosificación y el vilipendio de las personas discapacitadas y las desdeñosas actitudes clasistas y racistas enmascaradas como ciencia. La culminación natural de este movimiento, como todo el mundo sabe, fue el horror de la eugenesia nazi. Así pues, el primer paso de la argumentación es practicar lo que los autores llaman una «autopsia ética» de este movimiento, preguntándose cuáles fueron sus errores morales y si éstos han de ser endémicos en todo movimiento que persiga el tratamiento y mejoramiento genético.

Tras un complejo y revelador análisis que nos recuerda, entre otras cosas, que la eugenesia moderna ha gozado de popularidad tanto en círculos progresistas socialdemócratas como entre la derecha reaccionaria, los autores concluyen que podemos separar, hasta cierto punto, la idea de mejorar genéticamente a las personas de los ideales terriblemente viciados de la antigua eugenesia. En primer lugar, aquellos eugenesistas no abrigaban ningún respeto por la libertad reproductiva; cualquier movimiento moderno debe partir de una posición de respeto. Por otro lado, la eugenesia antigua no tenía modo de intervenir en el proceso reproductivo excepto controlando quién tenía hijos con quién. La eugenesia moderna tendrá abierto un campo mucho más amplio para el mejoramiento mediante la elección individual, pues las intervenciones genéticas y las modificaciones terapéuticas del genoma se pondrán a disposición de los padres del mismo modo en que actualmente se ofrecen otros tratamientos, 
y se regirán por parecidas reglas de consentimiento informado. Este tipo de tratamientos seguirán despertando interrogantes en torno a la libertad - por ejemplo, tendremos que preguntarnos si se debería obligar a los padres a practicar alguna intervención genética en un niño in utero; pero estas cuestiones serán parecidas a aquellas a las que ya nos hemos enfrentado cuando discutimos en torno a qué tratamientos médicos puede exigirse que los padres proporcionen a sus hijos, so pena de ser acusados de maltrato y negligencia.

La cuestión del prejuicio contra ciertos tipos de personas es mucho más espinosa, y los autores insisten en que toda sociedad justa debe ser muy respetuosa con las diferentes formas de concebir qué constituye una buena persona y en qué consiste una vida que merece ser vivida. También están muy atentos a la delicada interacción entre individuo y ambiente: insisten en que un defecto se convierte en una discapacidad sólo sobre el trasfondo de un entorno social concreto, y generalmente es posible idear un entorno en que un defecto cualquiera al menos suponga una discapacidad de menor grado. (Las rampas para sillas de ruedas, los accesos en los autobuses para sillas de ruedas y otras medidas por el estilo hacen que los problemas de movilidad incapaciten mucho menos a aquellos que han de valerse de dichas sillas de ruedas). Así pues, la elección de un entorno social siempre conlleva elecciones a favor de algunas personas y en contra de otras.

En todo caso, estos hechos no suponen que todo tratamiento y mejoramiento genético estén esencialmente ligados a formas nefastas de prejuicio y desprecio. Incluso en una sociedad pluralista y liberal tenemos que ponernos de acuerdo en torno a una lista de «bienes primarios» básicos que generalmente estimamos que constituyen preciosos requisitos esenciales para la realización de la mayoría de nuestros planes de vida. En este sentido, los autores se muestran optimistas respecto a que podamos dar con un elenco de capacidades humanas básicas, a las cuales todos los ciudadanos tengan derecho como un requisito ineludible para funcionar y hacer elecciones propiamente dichas. No tomar en consideración estas capacidades básicas es en sí iliberal, ya que esto socavaría la oportunidad real de las personas para elegir la vida que quieren. (Me hubiera gustado que los autores dedicaran más tiempo a evaluar el «enfoque de las capacidades» en relación a cuestiones de justicia social básica, el cual sostiene que el bienestar debería medirse no atendiendo a los recursos rawlsianos, sino más bien indagando qué es lo que la gente realmente es capaz de ser y hacer ${ }^{3}$.

${ }^{3}$ Para ver mi propia versión de este enfoque véase Women and Human Development: The Capabilities Approach (Nueva York, Cambridge University Press, 2000). Discuto las implicaciones del enfoque de las capacidades en cuestiones de discapacidad en «The Future of Feminism Liberalism», Proceedings and Addresses of the American Philosophical Association, núm. 74, 2000, pp. 47-79. Existe una traducción española publicada como «El futuro del liberalismo feminista», en Areté (Lima, Perú), vol. XIII, 2001, pp. 59-101. Discutiré estas cuestiones más adelante en mis Tanner Lectures, que tendrán lugar en Canberra, Australia, en noviembre de 2002, «Beyond the Social Contract: Toward Global Justice». 
La lógica de sus intereses les conduce a usar el lenguaje de las capacidades, pero aun así no evalúan el alcance de este otro enfoque teórico).

\section{III}

Sirviéndose de su análisis de las capacidades humanas más importantes como un «umbral», los autores a continuación abordan la complicada cuestión de cómo puede protegerse la igualdad de oportunidades en un momento en que los ricos pueden adquirir no sólo mercancías, sino también mejores cualidades personales. La igualdad de oportunidades es un concepto desconcertante incluso en las mejores circunstancias, pero deviene todavía más desconcertante cuando tenemos la capacidad de modificar a la persona. Los autores consideran dos conocidas concepciones de la igualdad de oportunidades. Una concepción (relacionada con la tradición ética kantiana) traza una línea entre la persona y el mundo, y sostiene que la igualdad de oportunidades se cumple cuando todos los aspectos sociopolíticos relativos al entorno se orientan en pro de la dignidad de todas las personas. Esta concepción podría incluso exigir algún tipo de redistribución de la riqueza y la renta de las personas que están mejor dotadas hacia las peor dotadas, tal como sin duda propone la versión de Rawls; pero se admite que las aptitudes sigan formando parte de la persona, por así decirlo, y no existe ningún motivo para proponer que las aptitudes valiosas sean objeto de redistribución, pues en cualquier caso todas las personas se consideran fundamentalmente iguales en dignidad debido a sus capacidades morales básicas.

Pero existe otra concepción de la igualdad de oportunidades más radical. Ésta afirma que las aptitudes, por sí solas, son sencillamente recursos: las personas no tienen derecho a poseerlos, y menos cuando éstos contribuyen a generar ventajas sociales o de clase. En nuestro mundo contemporáneo, todo lo que podemos hacer es redistribuir la riqueza y los ingresos, ya que no existen posibilidades reales de equiparar los talentos. Pero supóngase que llegamos a ser capaces de equiparar los talentos: iesa misma igualdad de oportunidades exigiría una ingeniería genética masiva para crear una nación formada por personas igualmente capaces?

Los autores emprenden una reflexión fascinante sobre esta cuestión así como sobre sus consecuencias sobre las propias teorías de la igualdad. Llegan a la conclusión de que somos afortunados: en realidad no tenemos que elegir entre estas dos teorías pues, en este punto, se interpone otro asunto ético que hace que las dos teorías den lugar a conclusiones parejas. Pues hemos de confrontar la teoría radical con el hecho del pluralismo valorativo: la gente abriga diferentes concepciones acerca de los fines últimos de la existencia humana, de ahí que surjan diferentes versiones de lo que debería ser una persona idealmente «capaz». Y si respetamos las diferentes religiones y otras concepciones del bien que sostienen nuestros conciudadanos, no podemos producir 
personas de manera que no se tenga en consideración estas diferencias. Así pues, volvemos a la lista de las capacidades humanas básicas que están presentes en todos los planes de vida: son simplemente éstas las que la teoría radical puede reivindicar justificadamente, y sólo hasta el límite de un nivel básico. De modo que esta alternativa es, después de todo, muy parecida a la teoría kantiana, pues la teoría kantiana también se centra en un elenco de habilidades básicas que, como los «bienes primarios», permiten a todos los ciudadanos perseguir sus propios planes vitales.

¿Cómo afecta esto a lo que los estados deberían ofrecer a la población? A continuación, los autores consideran la problemática distinción entre el tratamiento de los defectos genéticos y el mejoramiento de un equipamiento genético normal. Esta distinción no les satisface mucho, puesto que es fácil traer a colación casos que la cuestionan. La persona A es de baja estatura debido a un tumor originado por causas genéticas que impide el funcionamiento de la pituitaria. La persona B es de baja estatura porque sus padres eran de baja estatura. Parece que A tiene un defecto, cuya corrección debería ser tratada, mientras que B, por otro lado, no tiene un defecto, y el tratamiento de su estatura constituiría un caso de «mejoramiento». Y eso que ambas afecciones tienen una causa genética, y ambas son fuente de sufrimiento y discriminación.

Por muy problemática que a veces sea la distinción, no obstante los autores creen que está justificado confiar en ella para proyectar una evaluación de lo que un plan sanitario justo debería ofrecer a todos los ciudadanos: un tratamiento de todos los defectos genéticos que conllevan una reducción significativa del funcionamiento normal de la especie, tal como se especifica en el enfoque de las capacidades básicas. Creen que los seguros de enfermedad deberían ofrecer dichos tratamientos, ya sea mediante una intervención genética in utero o mediante tratamientos posteriores al nacimiento. Argumentan que es mucho más problemático ofrecer mejoramientos, y sostienen que dichos mejoramientos, tales como el aumento de la inteligencia o del talento musical de los hijos, podrían de hecho ser ilegales, dado que constituirían maneras en que los privilegiados crearían niños mejores que los del resto, violando así el espíritu mismo de la igualdad de oportunidades.

El enfoque de los autores sobre la igualdad de oportunidades, como quizá todos los enfoques filosóficos anteriores, se basa en una noción de humanidad común, si bien son plenamente conscientes de que con el tiempo la nueva genética puede cuestionar estas bases. Se preguntan cómo sería el mundo si grupos étnicos o religiosos fuesen capaces de planificar su descendencia de manera que ésta desarrollase rasgos apreciados por dichos grupos, hasta que al final aparecieran tipos humanos separados y abandonáramos el recurso ético que supone la noción de habilidades y necesidades compartidas. Sostienen con razón que esta eventualidad amenazaría las bases mismas de la moralidad. A este respecto tenemos buenas razones para temer el futuro, si bien no queda del todo claro qué deberíamos hacer para conjurarlo. 


\section{IV}

Inevitablemente, las discusiones en torno a las elecciones de los padres con respecto a los hijos con problemas genéticos constituyen una seria amenaza para los propios afectados. Aun cuando estas elecciones no supongan acabar con niños enfermos ya nacidos -incluso si, como en el primer caso que presentan los autores, éstas suponen ante todo curar discapacidades en el útero o después del nacimiento-, resulta preocupante que el síndrome de Down, la sordera y la ceguera dejen gradualmente de existir. Las personas que padecen estas afecciones no sólo temen un aumento de la estigmatización y de las carencias de protección social, sino que sostienen enérgicamente (especialmente en el caso de los sordos) que ellos tienen una cultura valiosa que será olvidada si se aplica de forma generalizada una única norma relativa a las capacidades humanas.

Los autores ofrecen una delicada exposición de estos argumentos pero finalmente los rechazan. No encuentran ninguna razón para conservar defectos que afectan seriamente al conjunto básico de capacidades humanas que aparece en su concepción del «umbral». Debe combatirse la discriminación y la estigmatización, por supuesto; pero aun así dudan de que deba realizarse condenando a futuros niños a la sordera o la ceguera una vez que sabemos cómo curar estas enfermedades. No rehusamos practicar inoculaciones a nuestros hijos o proporcionarles los tratamientos médicos que necesiten porque nuestros actos pudieran estigmatizar a otros enfermos o afectados. Arguyen que tampoco deberíamos vacilar en hacer que un niño viese u oyese si no pudiera hacerlo de otro modo. Hay muchas afecciones sobre las que podríamos discutir, ya que involucran valores controvertidos; pero existe un corpus de habilidades humanas básicas, y no tener alguna de ellas significa estar en desventaja en cualquier mundo remotamente similar al nuestro. La sociedad puede operar numerosos cambios que aumenten las oportunidades de los enfermos; pero no es posible hacer que la sordera y la ceguera dejen completamente de constituir una incapacidad. Es más, realizar adecuadamente tales cambios resultaría excesivamente caro, de modo que debemos cuestionarnos por qué tendríamos todos que correr con los gastos sólo porque algunos padres valoren la peculiar cultura promovida por una determinada incapacidad.

Éstas son las cuestiones más delicadas y difíciles que plantea el libro, y me parece que es aquí donde el admirable sentido práctico del análisis de los autores deja al lector sumido en la mayor perplejidad. Y es que la vida humana siempre ha sostenido una lucha contra los límites de la naturaleza, y cada uno de los seres humanos es el resultado de dicha lucha. Es más, sabemos que muchas de las vidas humanas más valiosas y creativas son el resultado de una lucha especialmente difícil que alejó a ciertas personas de lo convencional y las convirtió en blanco del desprecio y el insulto de sus iguales. Cualquiera que haya sido un mal deportista, o que tenga un físico 
diferente de cierto estereotipo sexual, sabrá que en estos «defectos» está presente un sufrimiento genuino - de modo que un progenitor bondadoso haría bien en realizar alteraciones genéticas para prevenirlos, dando lugar así a una nación de mujeres con grandes pechos y hombres musculosos. Pero ino debería cambiar más bien la cultura que la naturaleza? ¿Y de dónde, en un mundo de estereotipos sexuales genéticamente modelados según el patrón de una cultura recalcitrante, surgirán los artistas e intelectuales? Si todos los niños pueden ser creados conforme a cualesquiera que sean las normas dominantes en la sociedad, ino se empobrecerá por ello la vida humana?

Mi hija nació con un defecto perceptivo-motor (no claramente genético, pero supongamos que sí) que claramente la situaría por debajo del umbral que delimita el «funcionamiento normal de la especie» según los autores. Se trata de un defecto lo suficientemente severo como para que cualquier madre decente hubiera optado, ex ante, por un «arreglo» genético. (Aprendió a leer con dos años y a atarse los cordones con ocho). Ha tenido que lidiar toda su vida con insultos y burlas. Su personalidad idiosincrática, dinámica, divertida y totalmente independiente es inseparable de estas luchas. No sólo no me gustaría, ex post, haber tenido otra hija diferente, sino que ni siquiera me gustaría que ella misma hubiera sido «arreglada». Dejando a un lado el amor materno (si es que se puede), sencillamente me gusta este tipo de persona, inusual y contracorriente, mucho más de lo que me hubiera gustado (o al menos así lo creo) la cabecilla de las animadoras que hubiera podido tener. Y con toda seguridad no deseo un mundo donde todos los padres «arreglen» a sus hijos de manera que nadie sea un raro, y eso aunque todos sabemos que la vida de los raros no es fácil.

Pero un momento, dicen los autores de From Chance to Choice con sentido práctico. Tú también sabes que muchas formas de injusticia dan lugar a personalidades sabias y profundas. E. M. Forster lleva razón cuando, en Maurice, representa a su protagonista como un hombre que de no ser por su homosexualidad y los prejuicios en contra hubiera sido un aburrido agente de Bolsa de clase media. La adversidad y la diferencia llevan a Maurice a la introspección, la perspicacia y la genuina individualidad. Y seguramente tú no quieres conservar la homofobia simplemente porque algunos aburridos agentes de Bolsa puedan mejorar a través del sufrimiento.

Ciertamente no, no quiero. Y creo que es muy bueno el que nuestra sociedad se haya convencido (si es que lo ha hecho) de que la homosexualidad no es una enfermedad que ha de ser tratada, sino una opción contra la que se han dirigido prejuicios irracionales - que se haya convencido de combatir el prejuicio en vez de erradicar la homosexualidad. Obviamente, en otro momento y en otro lugar puede haber sido de otra manera. (De hecho, algunos partidarios de la eugenesia tuvieron esa esperanza, y muchos gays y lesbianas siguen temiendo que el conocimiento genético pueda ser usado algún día para erradicarlos). El problema es que no confío en que la sociedad emprenda esta vía con los 
prejuicios contra los bajitos, los descoordinados, las mujeres con poco pecho y los malos atletas. Es más probable que unos buenos padres se sientan obligados no tanto a luchar contra los prejuicios sociales que hacen la vida de estos niños difícil, sino más bien a «arreglar» estas afecciones, si pueden, antes del nacimiento.

Nuestro mundo, ya limitado por la tiranía de la conformidad, podría ser más pobre debido a tal cambio. ¿Qué habría dicho Mill si hubiera podido contemplar un mundo en el que el conformismo de la clase media pudiera no sólo comprometer la felicidad de algunas personas raras, sino su propia existencia en generaciones futuras? ¿Qué desafíos a las normas sociales dominantes, qué «experimentos de vida» podríamos esperar en un mundo así? «A ellos les gustaría que yo no hubiera nacido», dijo mi hija al oír que los autores de este libro eran partidarios del tratamiento genético de defectos que se apartan de un «funcionamiento humano normal». Pues bien, sí: en un cierto sentido sí. Pero dada la opción de ahorrarle a sus hijos futuros sufrimientos, ¿quién podría no estar de acuerdo con ellos sin titubear? Lo que ocurre es que el solo hecho de tener esta opción parece amenazante y de alguna manera trágico.

Yo no tengo una buena propuesta alternativa a las prudentes sugerencias de los autores. Creo que tienen razón al emplear un conjunto básico de habilidades humanas comunes como umbral para la actuación de la medicina genética, y proteger el pluralismo de los planes de vida por encima de dicho umbral. Pero deberíamos tener presente que probablemente los padres son jueces inadecuados para decidir qué entra en ese conjunto básico de lo humanamente normal; y también que podrían ser excesivamente celosos de la normalidad a expensas de muchas cosas buenas de la vida humana.

Apenas estamos empezando a crear una sociedad en la que se respeta como individuos a los niños con síndrome de Down, en la que se aprecia que los sordos tienen una cultura. Debemos apoyar estas conquistas contra la predecible oleada de demandas para normalizar el tratamiento genético. Aun sin prohibir intervenciones genéticas del tipo de las que recomiendan los autores, deberíamos alimentar una cultura pública en la que un amplio abanico de supuestas discapacidades sean respetadas, comprendidas y vistas con imaginación, como formas valiosas de vida humana —así, los padres ansiosos por lo «normal» lo pensarán dos veces. Los autores de este importante libro tienen razón en no idealizar la diferencia cuando ésta viene acompañada de grandes penas y graves impedimentos. Pero aquellas personas que se formaron, se fortalecieron y alcanzaron el éxito por su propia diferencia - por ejemplo, los que se convirtieron en pensadores porque no podían ser líderes- debieran reflexionar sobre su complicado pero feliz destino, y tratar de preservar un mundo donde eso le siga ocurriendo a otros. 